\title{
AS JANELAS DISCRETAS DE ALEXANDRE O'NEILL
}

\section{ALEXANDRE O'NEILL'S RARE WINDOWS}

JOANA MATOS FRIAS*

jfrias@letras.ulisboa.pt

Quadros, quadrinhos e desenquadros, fotografias de janelas, persianas e defenestrados: em 1981, o livro de Alexandre O'Neill As Horas já de Números Vestidas reúne uma sequência de composições que parecem querer dar resposta aos versos anteriores de $A$ Saca de Orelhas "Onde começa um poema? / (...) // No espaço quadrado da folha de papel? / (...) // Ou no espaço redondo em que te moves?". Nesse conjunto, a série escrita "para fotografias de Irene Buarque" cumpre uma evidente função de regência que requer a devida iluminação.

Palavras-Chave: Alexandre O’Neill; Irene Buarque; poesia; fotografia; arquitectura; janela; estilo tardio.

Frames, comics and unframes, photographs of windows, blinds \& etc.: in 1981, Alexandre O'Neill's book As Horas já de Números Vestidas brings together a sequence of compositions that seem to want to respond to his previous verses "Where does a poem begin? / (..)// In the square space of the sheet of paper? / (...) // Or in the round space in which you move?". In this set, the series written "for photographs by Irene Buarque" fulfills a very clear directing function which requires a proper enlightenment.

Keywords: Alexandre O’Neill; Irene Buarque; poetry; photography; architecture; window; late style.

Data de receção: 15-06-21

Data de aceitação: 03-08-2021

DOI: $10.21814 / 21.3474$

*Professora Associada, Universidade de Lisboa, Faculdade de Letras, Departamento de Literaturas Românicas/Centro de Estudos Comparatistas. ORCID: 0000-0001-5531-8436 
Rather than words comes the thought of high windows: The sun comprehending glass, And beyond it, the deep blue air, that shows Nothing, and is nowhere, and is endless. - Philip Larkin, "High windows"

O sol da manhã é enganoso meio mágico, gaio inventa se, invade a quadrada abertura por onde ele é avistado e vê, fenestreca. - Guimarães Rosa, "Quadrinho de estória"

Não haverá nada de muito podre No Reino da Dinamarca de Alexandre O’Neill, mas alguma providência terá de decidir se o facto de um poeta se interessar por alumínio ao aproximar-se do fim da vida - e da obra - não poderá empobrecer, ou apodrecer, a poesia. Vem esta consideração a propósito de "Poentes e nascentes de alumínio", a promessa metafórica que dá título a uma das crónicas que O’Neill assinou na rubrica "A escrita por medida", essa "espécie de rom rom" com que colaborou no Jornal de Letras a partir de Novembro de 1983; a leitura do texto, porém, cedo resgata o leitor de tal ilusão metafórica, uma vez que as preocupações do cronista são, de facto, não com a sua obra mas com os mestres de obras de Lisboa, ou com aquilo a que ele próprio chama os "mistérios da construção civill", e a essa luz o título pode ser descodificado metonimicamente:

Por estes andares - lê-se na abertura do texto -, Lisboa vai ter, não tarda muito, poentes e nascentes de alumínio. Marquises, caixilharias de janelas ou de montras, portas de estabelecimentos estão a passar-se, paulatinamente, para o alumínio. A luz nascente ou ocasional da cidade vai mudar. E nós vamos ajudar. Já não bastava mandarmos encaixilhar os nossos emblemas culturais (gravuras, desenhos, cartazes, fotografias) em alumínio. Temos de pôr bem à vista que o alumínio (tão prático!) é o futuro de todo o tipo de caixilharia, interior ou exterior. (O’Neill, 1985, pp. 271-272)1

Uma leitura apressada da peça induz o leitor a concluir que O'Neill é um escritor maduro com preocupações urbanísticas, o que pode suscitar o estranho desenho tardio de um poeta-vereador que escreveria impulsionado por cuidados de cidadania face ao progresso da sua cidade, a ponto de ser levado a instigar os entusiastas do material: "Se gosta assim tanto de alumínio, crie uma cidade só para si própria e ponha-lhe o inevitável nome: ALUMINIÓPOLIS". Mas esta leitura e a força perlocutória da injunção final têm uma validade tão precária quanto a que subjaz aos poemas de O’Neill espalhados por Lisboa que Miguel Tamen invoca na Introdução ao volume das Poesias Completas (Tamen, 2000 , p. 9 ss.), pelo que me parece que, a existir um problema da habitação aqui enunciado, ele está longe de ser de ordem social, e todo se poderia formular nesta passagem: "Já não bastava mandarmos encaixilhar os nossos emblemas culturais (gravuras, desenhos, cartazes, fotografias) em alumínio. Temos de pôr bem à vista que o alumínio (tão prático!) é o futuro de todo o tipo de caixilharia, interior ou exterior". Se é certo que o alumínio e o mau-gosto generalizado que ele denuncia cumprem para O’Neill um papel muito similar ao que desempenha o plástico nas sílabas do "Portugal" da sua Feira Cabisbaixa (cf. O'Neill, 2000, p. 211) ou nas Mitologias de Roland Barthes - onde "a hierarquia das substâncias é abolida, uma única as substitui a todas: o mundo inteiro

\footnotetext{
${ }^{1}$ Texto originalmente publicado no Jornal de Letras, Artes e Ideias, Ano IV, n. ${ }^{\circ}$ 97, de 15.05.1984, p. 31.
} 
pode ser plastificado, e a própria vida, já que, ao que parece, se começa a fabricar aortas em plástico" (Barthes, 1957, p. 161; trad. minha) -, parece mais certo ainda que a cisma do escritor será afinal, não só com o material, mas com a própria "caixilharia, interior ou exterior". E agora sim, talvez se faça legítima a interpretação metafórica, a menos que prefiramos reconhecer em O'Neill uma especial e quase pioneira competência arquitectónica para pensar sempre em janelas duplas; a verdade é que no início de um outro texto cronístico incluído em Uma Coisa em Forma de Assim ("O pesadelo", de 1972), também podemos ler "Talvez estes sejam arquitectos por fora e o que eu precisava agora era de arquitectos por dentro" (Bom, 2006, p. 268).

Ora, o que parece ser particularmente interessante no modo como O'Neill se posiciona no problema é que a sua técnica é claramente a do observador defenestrado, que não prevê sequer a possibilidade, de tradição realista-naturalista, de se encontrar num espaço interior que encaixilhe a paisagem exterior na moldura da janela a fim de compor uma cena ou desencadear uma dinâmica narrativa (o que com certeza o faria desconfiar daquela frase perfeita segundo Kafka, "Ele olhou pela janela"). Quer isto dizer que os poentes de alumínio, se não autorizam a tal leitura metafórica que se fundaria numa promoção de identidade entre o crepúsculo e o metal, também não permitem que, de acordo com o que uma codificação literária convencional sugeriria, se veja neles uma contaminação por contiguidade: os poentes e nascentes serão de alumínio, não porque o alumínio os enquadre, mas graças ao efeito de desenquadramento do alumínio que neles ou por eles se refracta. O exercício faz-se assim no sentido aparentemente inverso daquele que é habitual, porquanto o observador se situa no infinito espaço exterior que sofre alterações físicas em virtude da interferência de uma espécie de hiper-janela-matéria, como de resto já ficara muito claro num texto dos anos 60 incluído no volume As Andorinhas não têm Restaurante e intitulado "O quido da quida": "O sol janelou nesse coturno momento e acendeu no cabelo do Asa de Corvo um brilho de biqueira de citadino em domingo de missa" (O’Neill, 1985, p. 300; sublinhado meu). ${ }^{2}$

De facto, dizer que o sentido é inverso acaba por ser também muito pouco rigoroso, porque uma tal inversão pressuporia ainda uma orientação do olhar propagando-se no sentido exterior $\rightarrow$ interior, esse olhar-voyeur através da janela indiscreta que, à semelhança do olhar-pintor que vê de dentro para fora, não vê a janela enquanto janela porque apenas vê através dela ou da sua transparência. Ora, quando O'Neill diagnostica que a "luz nascente ou ocasional da cidade vai mudar" por efeito do alumínio, o que na verdade acontece é que ele suprime toda essa função limítrofe tradicionalmente atribuída aos elementos liminares, quer no que respeita à passagem entre espaço interior e espaço exterior - ou privado e público -, quer no que respeita às fronteiras impostas ou propostas pelo princípio do enquadramento que faz da janela (ainda antes da fotografia) a primeira e mais literal televisão, ${ }^{3}$ o que de certo modo também ajuda a mudar a luz que incida sobre títulos como Entre a Cortina e a Vidraça (1972) ou De Ombro na Ombreira (1969).

Claro que tudo isto poderia ser de importância nula se não fosse a coincidência pouco aleatória de aquela crónica ser a variação rom rom de um motivo quase obsessivo para O’Neill na sua produção poética da passagem dos anos 70 para os anos 80, e exemplarmente concretizado nas composições destinadas a dialogar com obras fotográficas de Irene Buarque e obras gráficas de Maluda, incluídas no volume As Horas já de Números Vestidas, de 1981. Aquilo que gostaria de começar por propor na abordagem desses poemas e do livro a que pertencem é a possibilidade de eles serem lidos como súmula

\footnotetext{
${ }^{2}$ Originalmente publicado no Diário de Lisboa a 12.12.1968.

${ }^{3}$ Como começou por defender Erving Goffman no seu estudo Frame Analysis: An Essay on the Organization of Experience, de 1974.
} 
ético-estética, no sentido que a ideia de súmula possa ter enquanto exposição da consciência do final de um ciclo, quer dizer, do final de uma obra (depois deste, O'Neill publica apenas 19 Poemas, em 1983), mesmo que, no caso em apreço, essa consciência não implique necessariamente o estabelecimento de uma ligação entre o estado do corpo empírico e o estado do corpo textual.

Em primeiro lugar, se a sugestão barroca do título do livro, emprestado a Góngora, vai sem dúvida ao encontro de uma preferência estético-literária de O'Neill, visível em muitos outros momentos e homenagens explícitas a autores barrocos - muito em particular espanhóis -, há aqui contudo uma inflexão que o intitulado sugere: já não se trata, como predominantemente em tributos anteriores, de insinuar uma aliança com uma determinada consciência virtuosa da construção que O'Neill tanto aprecia e que tem decerto o seu exemplo mais emblemático na paródia do célebre meta-soneto de Lope de Vega "Un soneto me manda hacer Violante", mas sim de no Barroco destacar um dos elementos tópico-temáticos mais preponderantes da atmosfera meditativa da época, o da passagem inexorável do tempo, seguramente ainda mais sedutora para O'Neill na formulação de Góngora devido à presença do advérbio "já”, tão do seu agrado. ${ }^{4} \mathrm{O}$ que talvez nos possa autorizar uma leitura do livro em chave tardia, mesmo que isso venha oferecer alguns problemas de difícil solução como:

i) As Horas já de Números Vestidas seria uma obra tardia em relação a que obra-prima anterior?;

ii) a natureza eventualmente tardia do livro seria expressão de "especial maturidade, um novo espírito de reconciliação e serenidade", "uma apoteose de criatividade artística e de poder", ou, pelo contrário, de "intransigência, dificuldade, contradição insolúvel", explorando uma "tensão não-harmoniosa, não-serena"? (cf. Said, 2006, passim)

ou

iii) será o autor-O’Neill ele próprio uma figura autoral tardia, no que isso possa explicar a natureza complexa e heterodoxa da relação com a sua época, em particular com a época entendida em limites histórico-literários, também eles sujeitos a "códigos totalizadores" (a expressão é ainda de Edward Said)?

É meu entender que o livro não traz consigo a aparição de um novo idioma. Mas talvez a sua índole recapitulativa seja detectável numa espécie de programa meta-idiomático especialmente flagrante nos conjuntos "Os defenestrados", "Persiana[s] para janela de Maluda", "Desenquadros" ou "Estórias quadradinhas", nos quais são identificáveis essas tensões não-serenas que a obra de O’Neill sempre alimentou, e que Óscar Lopes terá diagnosticado acutilantemente ao classificá-lo como um "surrealista neo-realista" (Lopes, 1993). Com efeito, quando em $A$ Saca de Orelhas o poema "Quatro lugares-comuns sobre várias artes poéticas" (O’Neill, 2000, pp. 385-387) vai fazendo desfilar "falsos dilemas"

\footnotetext{
${ }^{4}$ Veja-se, por exemplo, a enunciação do problema no texto "Uma arte do pormenor ou um preâmbulo para desatentos", incluído em Já cá não Está quem Falou (pp. 50-51): “À consciência da fugacidade do tempo, da transitoriedade de tudo, pode reagir-se de infinitas maneiras. A minha pessoal maneira de reagir (e peço perdão dela vir ao caso) é a amarração do efémero do tempo e do sítio em que, por insondáveis carambolas, me é dado viver. Mas o efémero que representa o meu aqui-agora e que eu, muito humanamente, desejo fixar (com todas as suas - e as minhas - contradições, opções, lutas, etc.), tem o seu peculiar décor, os seus adereços, as suas típicas personagens, a sua acção, os seus dizeres. Se eu não me pormenorizar neles, ao mesmo tempo deles tomando distância mediante uma operação de sobrevivência chamada ironia, que testemunho darei a mim mesmo (a mim mesmo como consciência angustiada da efeméride da minha vida) do tempo-sítio que é o meu para mim?”.
} 
antiquíssimos e idênticos como o da polaridade entre "inspiração" e "suor", ou o da identidade entre "silêncio" e "página em branco", torna-se muito claro que a composição se organiza em torno de um desassossego estrutural para O’Neill - não o mais explícito dos tais "lugares-comuns", mas o do lugar incomum que o poeta ocupa. É o que revelam versos como "O modelo exterior deixa-te definitivamente fora,/ mas fora de ti próprio", "(Nem a ti próprio te dês em espectáculo/ sob pretexto de reflexão.)", mas, muito particularmente, os versos indagativos que encerram o exercício:

Onde começa um poema?

Quando começa um poema?

No espaço quadrado da folha de papel?

No momento em que pegas da caneta?

Ou no espaço redondo em que te moves?

Ou quando, alheio a tudo, te pões de cócoras,

a coçar, perplexo, a cabeça?

Estamos no volume imediatamente anterior a As Horas já de Números Vestidas, e deixarei por agora de parte a imagem final do escriba acocorado, quer porque aquilo que ela pode sugerir foi já devidamente estudado por Joana Meirim na sua tese Literatura e Posteridade: Jorge de Sena e Alexandre O'Neill, quer porque me interessa mais, neste momento, destacar aquele "alheio a tudo" que surge como a derradeira alternativa que forneceria a explicação genesíaca do poema. As perguntas são jornalísticas - onde?, quando? -, e as possibilidades disjuntivas de resposta prolongam os tais dilemas que, sendo falsos, têm aqui uma aparência bastante verdadeira. A acreditarmos na mútua exclusão que as disjuntivas promovem, o acto poético teria de se explicar entre uma solução vinculada à escrita num sentido muito (cali)gráfico ("no espaço quadrado da folha de papel", "no momento em que pegas da caneta") contra uma solução aparentemente desvinculada da escrita ("no espaço redondo em que te moves", "alheio a tudo"), o que, de certa forma, não deixa de sugerir uma contraposição entre o acto de escrever e o acto de coçar a cabeça, isto é, entre a escrita enquanto negócio e a perplexidade enquanto ócio. O’Neill verbaliza aqui questões que, como sabemos, o atribulam desde o início da actividade literária, e aquilo que me parece muito digno de nota é que esta formulação sistemática de problemas que lhe são essenciais, embora resulte de uma notória capacidade auto-reflexiva maturada, tem ainda uma expressão manifestamente dubitativa que, malgrado o carácter especulativo, não deixa de ser ainda sintoma de intranquilidade.

Neste sentido, A Saca de Orelhas cumpre uma função mediadora entre a obra anterior composta por todos os livros até Entre a Cortina e a Vidraça e a breve obra posterior que As Horas já de Números Vestidas inaugura em 1981- não será aliás de somenos importância que sete longos anos separem $A$ Saca de Orelhas da colectânea que a antecede, o que só acontecera no início da obra, fazendo com que depois da publicação de Entre a Cortina e a Vidraça O'Neill tenha começado de servir outros sete anos. E aquilo que parece mais evidente neste rito de passagem é que a sequência "Os defenestrados" - que actualmente figura na obra apenas com a indicação epigráfica "Para fotografias de Irene Buarque", mas sem a companhia material das imagens a que é dedicada (O'Neill, 2000, pp. 452-459) - pode ser lida como uma sequência de lugares incomuns sobre várias artes poéticas e outras várias artes, se no entanto não suprimirmos da equação o diálogo interartístico de que ela efectivamente partiu e que de facto não é esquecido ao longo das 16 estrofes-janela de versos habilmente proseados, para usar os termos que o próprio O’Neill aplicou a Cesário Verde na sua célebre “Autocrítica” (O’Neill, 2000, p. 248). 

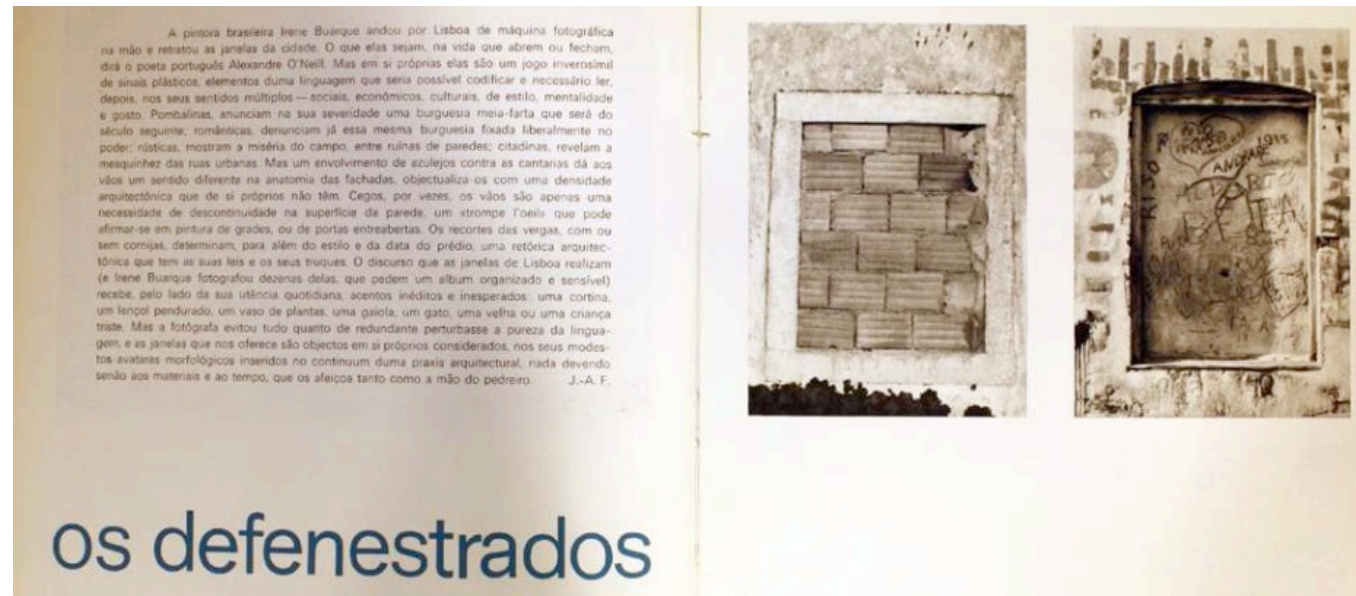

\author{
fotografias de Irene Buarque \\ texto de Alexandre O'Neill
}
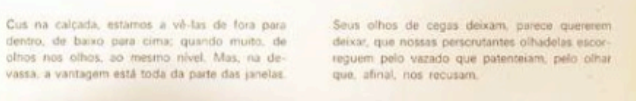

Fig. 1 Colóquio/Artes, Lisboa, Junho de 1977, pp. 24-25

Consideremos então que existem pelo menos dois objectos distintos intitulados "Os defenestrados" na obra de Alexandre O'Neill. O primeiro deles, que podemos sem receio designar por original, foi publicado nas páginas da Colóquio/Artes: revista bimestral de artes visuais, música e bailado em Junho de 1977, na companhia material das imagens fotográficas de Irene Buarque a partir das quais os poemas teriam sido compostos. ${ }^{5} \mathrm{O}$ segundo passará posteriormente a integrar a obra poética do Autor, desacompanhado dessas imagens, que se tornam presentes apenas mediante um exercício de convocação mental suscitado pela dedicatória-epígrafe "para fotografias de Irene Buarque", indicativa do processo transpositivo, mas também, e talvez sobretudo, graças à forma geométrica que os poemas assumem, e que não coincide com a que apresentavam inicialmente nas páginas da revista. ${ }^{6}$ Quer isto dizer que, num plano imediato, entre a publicação original e a versão definitiva a que hoje temos acesso deixou de ser observável um procedimento de combinação medial fundado na articulação entre dois meios efectivamente díspares e hetero-autorais (imagens de Irene Buarque-palavras de Alexandre O'Neill), para se verificar uma operação mutativa do próprio poema, que agora preserva esse acto de combinação medial integrando-o na mancha gráfica, isto é, fundindo os dois meios - visual e

\footnotetext{
${ }^{5}$ Colóquio Artes: revista bimestral de artes visuais, música e bailado, 33, $2^{\mathrm{a}}$ série / $19^{\circ}$ ano, Lisboa, Fundação Calouste Gulbenkian, Junho de 1977. O contexto e as características principais desta publicação foram detalhadamente estudados por Sara Lacerda Campino na sua Dissertação O Experimentalismo na Obra de Alexandre O'Neill (2011, p. 92 ss.), na qual a Autora informa que O’Neill terá escrito “Os defenestrados" a pedido de José-Augusto França.

${ }^{6} \mathrm{Na}$ descrição detalhada de Sara Campino (op. cit., p. 87): “Quando surge na Colóquio Artes, o poema é colocado em relação directa com reproduções das fotografias de Irene Buarque, num formato imagemlegenda, ao longo de oito páginas, verificando-se que tanto o número, a dimensão e disposição das fotografias, como as da mancha do texto, se alteram em cada conjunto de duas páginas. Pelo contrário, quando o poema integra a antologia deixa de estar em relação directa com a imagem, e a mancha de texto adquire uma presença regular ao longo das oito páginas, configurando-se como dois quadrados sobrepostos e alinhados verticalmente, com sete linhas cada. A leitura formal da linha sobrepõe-se quer ao ritmo do texto em prosa, quer à apreensão do seu sentido, através da supressão de hífenes da translineação e do preenchimento com palavras da extensão total da frase, até aos limites do alinhamento justificado, eliminando deste modo eventuais quebras visuais sem, no entanto, inviabilizar a compreensão do texto".
} 
verbal - numa totalidade híbrida, indiscernível, icónica e autoral (textoimagem de Alexandre O’Neill). ${ }^{7}$

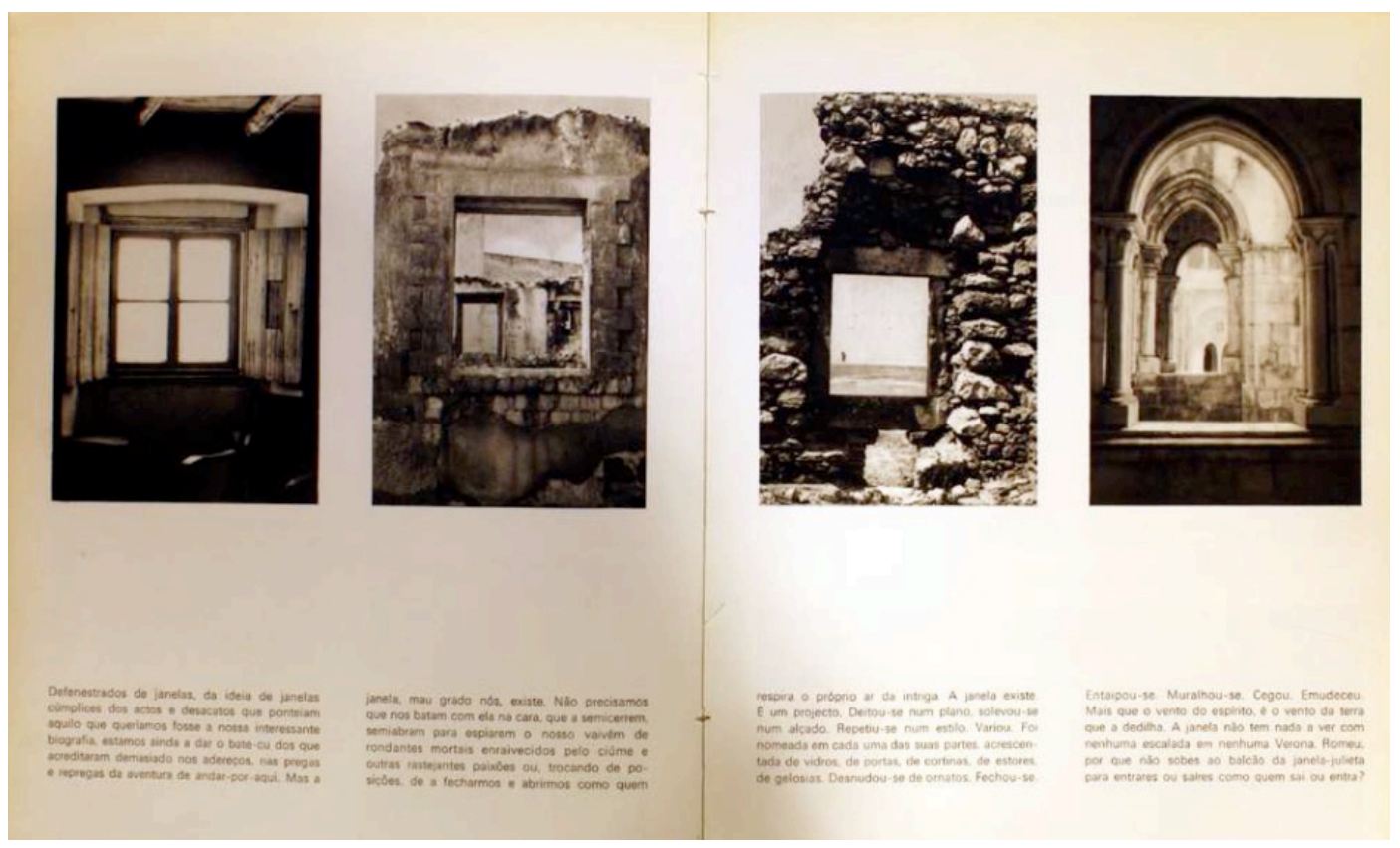

Fig. 2 Colóquio/Artes, Lisboa, Junho de 1977, pp. 30-31

Ora, não me parece pertinente aplicar a estas composições o princípio formulado pelo próprio O'Neill a propósito do jogo de legendar fotografias que praticou no âmbito da sua "preocupação de inventariar", conforme anunciou num contexto mais especificamente jornalístico: "aqui deixo um lote de legendas de fotografias de magazine que, para serem compreendidas nas suas intenções, 'dispensam' perfeitamente as imagens fotográficas de que eram acompanhantes...” (O’Neill, 2008, p. 102). ${ }^{8}$ É certo que há também na edição definitiva de "Os defenestrados" um gesto que é da ordem da "dispensa", mas julgo que ele obedece a um outro tipo de preocupações. Numa leitura imediata, a postura enunciativa que O'Neill adopta aproxima-se muito daquilo que Rainer Maria Rilke fez no conjunto de poemas em francês "As janelas" (Rilke, 1997, p. 1135 ss.) - curiosamente, criação madura produzida literalmente num novo idioma,$-{ }^{9}$ uma vez que ambos se abstêm de um exercício descritivo (quer dizer, ecfrástico) convencional para privilegiarem uma interpelação similar à praticada por Keats na famigerada "Ode on a Grecian Urn", ainda que a equivalência seja mais pertinente no caso de Rilke, que se dirige à janela quase como Julieta quando suspira "Then, window, let day in, and let life out". Em

\footnotetext{
${ }^{7}$ Faço uso da tipologia estabelecida por W. J. T. Mitchell, na qual propõe que se marque ortograficamente a distinção entre três diferentes modos/níveis de relação entre texto e imagem: texto/imagem (ruptura), texto-imagem (relação) e textoimagem (síntese) (Mitchell, 2012, p. 1 ss.).

${ }^{8}$ É também neste contexto que encontramos as peças redigidas em torno de fotografias divulgadas n' $A$ Capital e hoje disponíveis (textos e imagens) nas páginas do volume Já cá não Está quem Falou (pp. 175192).

${ }^{9} \mathrm{Na}$ Introdução à edição brasileira destes poemas de Rilke, Mário Alves Coutinho questiona-se precisamente: "Por que um poeta que levou o alemão à perfeição (de acordo com a afirmação de Robert Musil) passou a escrever em outra língua (...) depois de terminar e publicar aquelas que foram, talvez, suas duas obras-primas (Elegias de Duíno e Sonetos a Orfeu)?” (in Rilke, 2009). E Guilherme Gontijo Flores destaca que, "no meio da fragilidade que o atormentou nos últimos anos, parece surgir, insegura, uma vitalidade poética crescente que culmina em mais de 400 poemas franceses escritos em quatro anos, entre 1922 e 1926, ano de sua morte".
} 
Rilke como em O'Neill, as janelas que a poesia canta constituem-se a partir de um procedimento crítico que evidencia e desconstrói a hipercodificação do motivo na história do pensamento e da arte ocidentais, desde a metáfora ciceroniana dos olhos-janelas da alma que Leonardo prolongará, até à eliminação leibniziana das janelas ou à fenestralidade da Fenomenologia, passando por todas as teorias e práticas pictóricas e narratológicas que, de Alberti a Balzac a Zola e a Henry James, converteram a janela em conceito operatório matricial da representação na ficção moderna, como exemplarmente sintetizam os versos de Rilke: 'N'es-tu pas notre géométrie,/ fenêtre, très simple forme/ qui sans effort circonscris/ notre vie énorme?". Quer dizer, ambos os poetas parecem admitir que a história da janela é muito mais a história de um dispositivo por vezes afim do fotográfico - tema ou tecnema de valor hermenêutico - do que a de um mero elemento arquitectónico e, ao fazê-lo, tornam a janela visivel na sua hipermediaticidade, confrontando assim a função mediadora assente na invisibilidade para que o papel de "janela da história" a foi remetendo. Escreve O'Neill no esboço do seu windows:

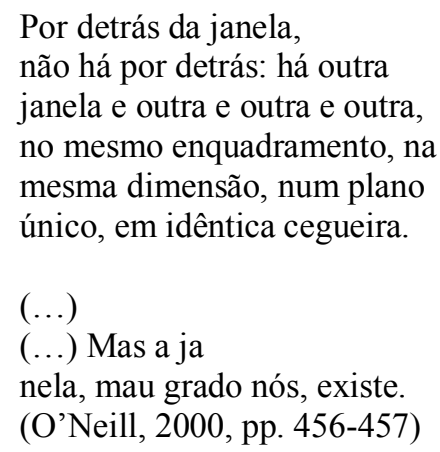

Se a constatação final deriva certamente de um impulso meditativo desencadeado pela própria obra fotográfica de Irene Buarque, uma vez que as suas janelas não integram qualquer presença denotativa de elementos humanos, a janela em cascata dos versos anteriores instaura uma lógica hipermedial que parece ser a configuração pós-moderna de um motivo pictórico e literário do século XIX muito pouco explorado nas diversas propostas que existem de sistematização de uma tipologia, e que por uma abusadora manobra de etimologia popular talvez pudesse estar na origem das janelas hipertextuais que o sistema operativo Windows veio metaforizar a partir de 1981, ano de publicação de As Horas já de Números Vestidas: é que numa boa parte das narrativas de genealogia realista que conhecemos, a janela, ao invés de funcionar como um furo que orienta o observador do interior para o exterior, existe para iluminar - ou desencadear - o acto de leitura (aspecto que é já decisivo em algumas telas flamengas, se pensarmos na célebre leitora de Vermeer), como acontece por exemplo num dos livros preferidos de O'Neill, $A$ Capital de Eça de Queirós, quando nos é contado que Artur passa os fins de tarde a ler encostado à janela do quintal.

Haveria então uma dobra a acrescentar ao sentido do espelho e da lâmpada no conhecido estudo de M. H. Abrams, o que talvez explique também que, num outro plano, quase arquitextual, interesse muito particularmente a O'Neill e também a Rilke aquilo que alguns especialistas têm qualificado como a função libidinal da janela (Lungo, 2014: passim), essa espécie de lei romanesca que se liga inextricavelmente ao topos deceptivo da mulher exposta, convertido em tropo por Rilke nos belíssimos versos "Fenêtre, toi, ô 
mesure d'attente, $/(\ldots)$ // Toi qui sépares et qui attires", ${ }^{10}$ e recuperado por O’Neill num retorno com desvio ao reino da Dinamarca
A janela não tem nada a ver com nenhuma escalada em ne nhuma Verona. Romeu, por que não sobes ao balcão da janela- -julieta para entrares ou saí res como quem sai ou entra? (O’Neill, 2000, p. 459)

que será ainda expandido num dos sonetos isabelinos dedicados às janelas de Maluda:

\author{
Esta janela já não tem enredos, \\ ninguém por ela espreita, ninguém espera \\ vê-la semicerrar, semiabrir \\ o olhoblíquo verde do ciúme;

Eis a declaração de óbito da transitividade da janela e da sua tarefa narratológica ("Esta janela já não tem enredos", "esta janela já não serve para nada"), pelo que, num plano imediato, O’Neill faz com a janela o que faz com quase tudo, resgata-a de uma certa doxa instituída, salvando-a do lugar-comum segundo o qual ela estaria reduzida a uma existência fronteiriça e a uma correlata tarefa simbólica de mediação dicotómica entre o privado e o público, a intimidade e a extimidade, o aberto e o fechado: "Cautela, amigos, com o olho mobilado pelo lugar-comum", alertava já na crónica "Olha o passaroco!", em 1974 (Bom, 2006, p. 215). Pouco dado a cisões dicotómicas, o que na verdade O'Neill promove neste muito singular exercício ecfrástico é uma meditação sobre as técnicas do artista-observador que lhe permite resolver - não no sentido de solucionar - algumas perturbações transversais a toda a sua obra, em especial as relacionadas com paradigmas de representação historicamente entendidos como antagonistas.

Mas aquilo que em O’Neill mais assombra é a coerência do programa, se pensarmos que o poema que publicou em 1944 nas páginas de $O$ Castelovidense já abria com os versos "Um dia hei-de ver se me levanto cedo/ para apanhar o mundo de janelas fechadas", projecto quase baudelairiano ${ }^{11}$ que no poema de 77 ganhará esta expressão tão precisa:

\footnotetext{
${ }^{10}$ E ainda, logo na abertura da sequência: "Il suffit que, sur un balcon/ ou dans l'encadrement d'une fenêtre,/ une femme hésite..., pour être/ celle que nous perdons/ en l'ayant vue apparaître".

${ }^{11}$ Cf. "Les fenêtres", em Petits Poèmes en Prose: "Celui qui regarde du dehors à travers une fenêtre ouverte, ne voit jamais autant de choses que celui qui regarde une fenêtre fermée. Il n'est pas d'objet plus profond, plus mystérieux, plus fécond, plus ténébreux, plus éblouissant qu'une fenêtre éclairée d'une chandelle. Ce
} 
Cus na calçada, estamos a vê-las de baixo para cima; quando muito, de olhos nos olhos, ao mesmo nível. Mas, na devassa, a vantagem es tá toda da parte das ja nelas. Seus olhos de cegas

deixam, parece quererem dei xar, que nossas perscru tantes olhadelas escorreguem pelo vazado que patentei am, pelo olhar que, afi nal, nos recusam. O pano correu. Defenestrados, som

os o olhar que as ja nelas de si próprias ex pulsaram. Olhamos de fora para fora, para o leitoso, o pedregoso, o cimentado, o entijolado, o entabuado, o encortinado, o opaco em

que as janelas se encerraram, se encegueceram. Janelas na da espelham do que é nosso. Ou espelham tudo: nosso es panto, nossa perplexidade, nos so medo. Molduras, écrans para o filme que desenrolamos

nos espaços onde a ambigui dade aceita enquadrar-se pelo tempo de uma contemplação ou duma interrogação. Nada se passa por detrás das janelas desde que deixámos de estar por detrás delas. À flor de

janela, só um trompe-l'oeil: a janela. (...)

(O’Neill, 2000, pp. 452-454)

O poeta assume a posição do operator que está na origem das imagens de Irene Buarque porque continua a interessar-lhe mais "apanhar o mundo de janelas fechadas" do que assistir como spectator ao "teatro-da-janela" de certas imagens-tempo cujo fim também diagnostica. Quer dizer: interessa-lhe mais a liberdade da reflexão do que o carácter impositivo da percepção visual que em certa medida subjaz a um paradigma em que a janela seria por excelência o tópico de accionamento de um descritivismo visando o efeito de real, uma espécie de materialização arquitectónica da objectiva fotográfica, em suma, a abertura para um espaço que se pretende objectivado. De acordo com este modelo, totalmente alicerçado num pressuposto de transparência que não admite a possibilidade do fechamento ou da opacidade, a janela é tão invisível como a fotografia enquanto tal

qu'on peut voir au soleil est toujours moins intéressant que ce qui se passe derrière une vitre. Dans ce trou noir ou lumineux vit la vie, rêve la vie, souffre la vie" (Baudelaire, 1968, p. 174). 
segundo Barthes, e não existe enquanto janela-imagem, também porque a sua transparência resulta sempre da função-metonímia que desempenha na sintaxe do edifício em que se inscreve. É precisamente este aspecto que as obras de Irene Buarque e de Maluda tendem a invalidar, conferindo à janela um valor objectal e sígnico autónomo, ${ }^{12}$ gesto aliás decisivo numa certa tendência da arquitectura contemporânea a partir de Le Corbusier: ${ }^{13}$

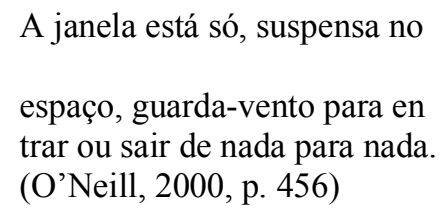

Neste sentido, o que o autor já sereno de "Os defenestrados" parece propor ao autor ainda agitado de $A$ Saca de Orelhas é que suprima as suas disjuntivas e conclua que o poema começa no espaço redondo em que o poeta se move também quando coça, perplexo, a cabeça, sem que isso invalide que o sistema operativo graças ao qual o poema arranca seja iniciado no momento em que o poeta pega na caneta para manchar o espaço quadrado da folha de papel. Ora, nesta proposta é absolutamente fulcral que o poeta seja verdadeiramente um defenestrado - nem sequer cortado ao meio como na conhecida imagem de André Breton -, se considerarmos que a tradição do homo fenestris ou do escritor à janela - com exemplos muito expressivos em contos de Hoffmann (Des Vetters Eckfenster) ou de Hawthorne (Sunday at Home) - é uma tradição que promove, como assinalou Jean Starobinski, uma imagem do espectador como consciência separada, já que vê tudo e não participa em nada, imagem que não pode deixar de nos remeter para a apreciação feita por Susan Sontag a propósito da complexa posição ético-moral do fotógrafo (Starobinski, 2016, p. 455; cf. Sontag, 1977). ${ }^{14}$

Não é com certeza por acaso que, no poema de O'Neill, "defenestrados, so/mos" todos. Se há convicção que a sua obra sempre transmitiu é a de que para ele ser poeta é ser poeta-no-mundo ${ }^{15}$ - mais por contacto do que por descrição, em termos russellianos -, e só assim se pode entender essa belíssima arte poética já inscrita No Reino da Dinamarca com o título "Poesia e propaganda" para lá da sua superfície paródica mais óbvia. Um poema que ilumina bem algumas afinidades electivas de O’Neill, sobretudo aquelas

\footnotetext{
${ }^{12}$ Muito recentemente, Irene Buarque revisitou a sua obra de quatro décadas com uma exposição não por acaso intitulada JanelaObjecto, patente na Fundação Calouste Gulbenkian.

${ }^{13} \mathrm{Na}$ síntese precisa de Décio Pignatari: “A janela, na arquitetura, é obviamente um signo metonímico que logo se metaforiza, quando tem, sob si, hipostasiado, o olho, pelo qual o edifício-gente olha e espia para fora, muitas vezes vedando a operação contrária, através dos mais variados artifícios, da cortina ao vidro espelhado. É um buraco na parede, diverso, porém, do buraco de uma porta, portão ou portal: por este vão e vêm corpos e objetos; pelo outro, espraia-se (ou concentra-se) o olhar. (...) Com o Beaubourg, de Piano e Rogers, começa uma outra história, pós-moderna, o sintagma de dentro virando sintagma de fora (intestinos para fora, pele para dentro). (...) Não tendo para onde ir, para onde foi a janela? Para o espaço, literalmente. (...) A janela venceu a parede, da qual, um dia, foi furo - e negação” (1995, pp. 10-11).

${ }^{14}$ Constatação que vai ao encontro do juízo de Fernando J. B. Martinho, proferido assim em "Alexandre O’Neill e Pessoa” (1987, p. 50): “a poesia de O’Neill não procuraria tanto elevar-se às alturas do surreal onde as contradições seriam anuladas, como situar-se criticamente perante o real, 'isto' aqui em baixo, mais adequado, decerto, ao 'falar' que ao 'imaginar', sem que isso, obviamente, implique admitir-se a redução da capacidade transfiguradora do real de que inevitavelmente se alimenta toda a visão lírica por mais objectivista que se pretenda".

15 António Ramos Rosa qualificou esta rara conciliação como "a dialéctica do sonho e do real", no título de um texto de 1986 onde sublinhava que a poesia de Alexandre O'Neill “é um conhecimento do real através de uma imaginação que se faz visão lúcida, actuante, participativa. (...) Assim, a poesia cumpre a sua vocação essencial: ser uma mediação fraterna" (p. 126).
} 
que lhe permitiram associar a admiração literária ao afecto pessoal, como aconteceu com Teixeira de Pascoaes, Vinicius de Moraes ou Ruy Cinatti, numa rigorosa concretização do princípio que transmitiu em entrevista a Clara Ferreira Alves, segundo o qual "A relação com as palavras é fundamental e a relação com os outros depende da relação com as palavras":

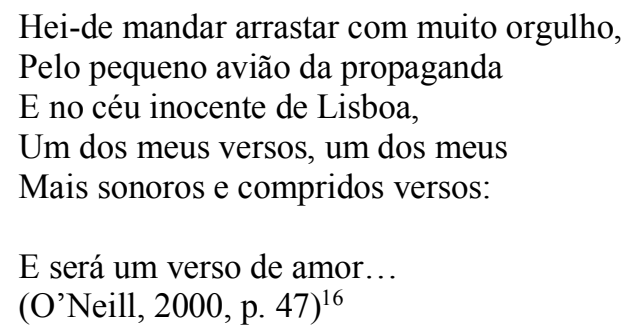

Num importante ensaio sobre os artistas e a velhice datado de 1954, Gottfried Benn recorda uma passagem de A Morte de Ticiano de Hofmannsthal, na qual o pintor, que continuava a criar no seu leito de morte, pede que lhe tragam as obras de juventude, e explica:

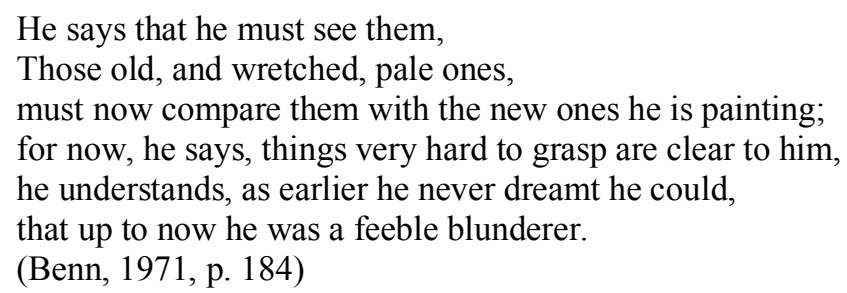

Não quero naturalmente sugerir que nos livros anteriores a As Horas já de Números Vestidas estivéssemos perante um O'Neill "feeble blunderer"; mas a passagem de Hofmannsthal diz muito sobre o impulso que preside à dicção seguríssima dos poemas desta colectânea de 81, nos quais a maior parte das coisas que eram "hard do grasp" anteriormente se tornaram claras para ele. Resta saber se isto se deve àquele princípio de Schlegel de acordo com o qual para se poder escrever bem sobre alguma coisa é preciso que ela já não nos interesse mais. E se este princípio se terá aplicado ou não ao tão especial desaparecimento das fotografias de Irene Buarque, convertidas em poemas de Alexandre O'Neill que são agora como janelas mal - e tão bem - situadas.

\section{REFERÊNCIAS}

Barthes, R. (1957). Mythologies. Paris: Seuil. (1998). A Câmara Clara. Lisboa: Edições 70.

${ }^{16}$ Leia-se ainda a esta luz versos tão extraordinários como estes de $A$ Saca de Orelhas:

Há uma gente que desponta do outro lado do vale.

Está a correr para cá.

São os meus semelhantes.

Com eles vou desentender-me (mais que certo!),

mas a ideia que deles faço

é ainda um laço.

(O’Neill, 2000, p. 344) 
Baudelaire, C. (1968). Euvres Complètes. Paris: Seuil.

Benn, G. (1971). Artists and old age. In Primal Vision: Selected Writings. New York: New Directions.

Bom, L. (2006). Alexandre O’Neill, Prosas de um Poeta: Proposta de edição crítica, vol. I. Lisboa: Faculdade de Ciências Sociais e Humanas da Universidade Nova.

Campino, S. L. (2011). O Experimentalismo na Obra de Alexandre O'Neill. Lisboa: Faculdade de Ciências Sociais e Humanas da Universidade Nova.

Goffman, E. (1986 [1974]). Frame Analysis: An Essay on the organization of experience, pref. Bennett M. Berger. Boston: Northeastern University Press.

Lopes, Ó. (1993). Cesário e O’Neill. In Cesário Verde: Comemorações do Centenário da Morte do Poeta. Lisboa: Fundação Calouste Gulbenkian.

Lungo, A. (2014). La Fenêtre: Sémiologie et histoire de la représentation littéraire. Paris: Seuil.

Martinho, F. J. B. (1987, Maio). Alexandre O’Neill e Pessoa. Colóquio/Letras, 97. Lisboa: Fund. Calouste Gulbenkian.

Meirim, J. (2014). Literatura e posteridade: Jorge de Sena e Alexandre O'Neill. Tese de Doutoramento em Teoria da Literatura. Lisboa: Faculdade de Letras.

(2018, Maio). O’Neill e o soneto. Colóquio/Letras, 198. Lisboa: Fund. Calouste Gulbenkian.

Mitchell, W. J. T. (2012). Image X Text. Introd. a The Future of Text and Image: Collected Essays on Literary and Visual Conjunctures, ed. Ofra Amihay e Lauren Walsh. Newcastle: Cambridge Scholars Publishing.

O’Neill, A. (1985). Uma Coisa em Forma de Assim. Lisboa: Assírio \& Alvim. (2000). Poesias Completas, introd. Miguel Tamen. Lisboa: Assírio \& Alvim. (2008). Já cá não Está quem Falou, ed. Maria Antónia Oliveira e Fernando Cabral Martins. Lisboa: Assírio \& Alvim.

Pignatari, D. (1995). Da não-janela à não-janela. Apres. de Luís Antônio Jorge, O Desenho da Janela. São Paulo: Annablume.

Rilke, R. M. (1997). CEuvres Poétiques et Théâtrales. Paris: Gallimard.

(2009). As Janelas, seguidas de Poemas em Prosa Franceses, ed. bilingue. Belo Horizonte: Crisálida.

Rosa, A. R. (1986, Setembro). Alexandre O'Neill ou a dialéctica do sonho e do real. Colóquio/Letras, 93. Lisboa: Fund. Calouste Gulbenkian.

Said, E. W. (2006, July 16th). On late style. The New York Times. https://www.nytimes.com/2006/07/16/books/chapters/0716-1st-said.html 
90 JOANA MATOS FRIAS

(2007). On Late Style: Music and Literature against the Grain. Nova Iorque: Vintage Books.

Sontag, S. (1977). In Plato's cave. In On Photography. Nova Iorque: Farrar, Straus \& Giroux.

Starobinski, J. (2016). La beauté du monde: La Littérature et les Arts. Paris: Gallimard.

Tamen, M. (2000). A poesia. Introd. a O'Neill, Alexandre, Poesias Completas.

(A autora segue a antiga ortografia.) 